\title{
A Note on the Role of Bank Capital
}

\author{
Alfred V Guender, Yuxuan Peng \\ Department of Economics and Finance, University of Canterbury, Christchurch, New Zealand. \\ alfred.Guender@canterbury.ac.nz
}

\begin{abstract}
This note explores how a bank's balance sheet responds to a capital shock in a simple model of the banking firm where both loan demand and deposits are sensitive to a bank's capital position relative to its competitors. An unconstrained bank shrinks its deposit base in the wake of a capital loss if loan demand is very sensitive to the bank's relative capital position. The deposits of an unconstrained bank expand only if both deposit and loan demands are fairly immune to a bank's relative capital position. In a simple model with reserves we show that in the wake of a capital loss the adjustment of loans and reserves under a binding constraint depends on the parameters of the model while the adjustment of total assets and liabilities does not. Loans decrease by the size of the capital loss plus the increase in reserves. If the constraint is not binding then loans generally decrease by more than the increase in reserves.
\end{abstract}

Key Words: deposits, loans, reserves, capital-asset ratio, balance sheet JEL Code: E51, G2

\section{INTRODUCTION}

It has been more than five years since the dramatic Lehman Brothers bankruptcy. Since then there has been a fierce debate inside central banks and regulatory agencies about what constitutes the right balance between two competing objectives. On the one hand, there is an express desire to protect the safety and soundness of the financial system while on the other there is the equally desirable goal of letting financial markets allocate financial resources effectively and smoothly without needless interference. Banks have been at the centre of this raging debate. Of all pressing banking issues the role of capital in regulating banks has probably received the most attention. The new Basel III accord requires a bank to hold more and better quality capital for its risk-weighted assets. In addition, banks are now subject to leverage ratios to mitigate the concern that they had too much leeway in calculating the riskweighted capital ratios. The new accord also requires banks to maintain liquidity ratios to lessen the risk of fire sales in case of a financial shock. ${ }^{1,2}$

The stricter capital requirements and additional regulatory provisions are intended to make the banking system safer. Incorporating these into a modern theory of the banking firm is a promising avenue for current and future research. Our aim in this note is to examine how a profit-maximizing bank responds to a loss of bank capital. We use a highly simplified oneperiod model along the lines of Peek and Rosengren (1995) to explore how a bank reacts to a worsening capital position in two scenarios: one where a bank is constrained by a regulatory capital-asset ratio and the other where it is not. They find that the composition and size of a

\footnotetext{
1 The Reserve Bank of New Zealand and the Swiss National Bank have also imposed loan-to-value ratios on the banking sector as a precautionary measure to keep house price inflation in check and to lessen the probability of a systemic crisis in the credit market.

${ }^{2}$ For a recent article on policy reforms in financial markets, see Arnold et al (2012).
} 
bank's balance sheet depends on whether or not the bank faces a binding capital constraint. For instance, in the wake of a loss of capital, an unconstrained bank expands its deposit base to avoid haemorrhaging loans while a capital constrained bank sheds deposits thereby shrinking its loan portfolio even more than in the unconstrained case.

This note introduces two important changes to the original model proposed by Peek and Rosengren. The first alteration attributes capital a more prominent role in determining assets and liabilities on a bank's ledger. A bank's deposit base depends on the bank's own capital position relative to its competitors'. A well-capitalized bank attracts more deposits because it is deemed safer by the public. The capital position of a bank relative to its competitors also affects its loan demand because a well-capitalized bank charges a higher lending rate than its competitors. These alterations turn out to have far-reaching consequences for how a bank responds to a loss of capital. In particular, a bank may no longer behave as suggested by the original Peek and Rosengren analysis. Indeed, a bank may shrink its deposit base even if the regulatory capital constraint is not binding and shrink the dollar value of its loan portfolio by more than the loss of capital. The other change to the model expands the set of assets a bank can hold. Apart from making loans, a bank can now also keep reserves which earn interest. In our set-up reserves are not held as a fixed proportion of deposits. Instead, reserves decrease as the difference between a bank's lending rate and the policy rate set by the central bank increases. In this expanded model, we show that in the wake of a capital loss the adjustment of loans and reserves under a binding constraint depends on the parameters of the model while the adjustment of total assets and liabilities does not. The amount by which the loan portfolio shrinks equals the size of the capital loss plus the expansion of reserves.

In the next section we elaborate on an expanded role for capital in the model. Section 3 introduces reserves into the model. Section 4 offers a brief conclusion.

\section{THE MODEL WITH AN EXPANDED ROLE FOR BANK CAPITAL}

The bank maximizes profits in a monopolistically competitive market. There is only one asset, loans $(L)$, and one liability, deposits $(D)$. There is only one form of capital, equity capital $(K)$, which for the purpose of this analysis is deemed exogenous. In the event of a capital loss the bank cannot compensate by issuing more equity. ${ }^{3}$ The balance sheet constraint is exceedingly simple:

$$
L=K+D
$$

The bank must maintain a minimum of capital relative to its asset base:

$$
K \geq \mu L
$$

\section{$\mu=$ Capital-asset ratio set by financial authorities 4}

The role of capital in the Peek and Rosengren model is extremely limited. Capital appears only in the balance sheet constraint and the capital- asset ratio constraint. It neither affects the bank's loan nor its deposit relation. But a case can be made for capital to affect the two relations directly. We therefore propose the following loan and deposit relations:

\footnotetext{
${ }^{3}$ On the role of capital, see Berger et al (1995). Why bank regulators care about bank capital is described in detail by Bhattacharya and Thakor (1993).

${ }^{4}$ A typical value would be 8 percent.
} 


$$
\begin{array}{ll}
D=f_{0}+f_{1}\left(r_{D}-\bar{r}_{D}\right)+f_{2}(K-\bar{K}) & f_{1}>0, f_{2}>0 \\
L=g_{0}-g_{1}\left(r_{L}-\overline{r_{L}}\right)+g_{2}(K-\bar{K}) & g_{1}>0, g_{2}>0
\end{array}
$$

$r_{D}=$ interest rate paid by bank on deposits

$\bar{r}_{D}=$ Interest rate offered by bank's competitors

$r_{L}=$ Interest rate charged by bank on loans

$\bar{r}_{L}=$ Interest rate charged by bank's competitors on loans

$\bar{K}=$ capital base maintained by bank's competitors

For given levels of capital and the deposit rate offered by its competitors, an increase in the deposit rate offered by the bank results in a higher deposit inflow. A bank with higher capital than its competitors also attracts more deposits as it is considered safer in the sense that it has a greater cushion to absorb write-offs. The appearance of capital in the deposit relation implies further that a bank's interest rate on deposit is negatively correlated to its capital base. Having more capital relative to its competitors allows a bank to offer a somewhat lower interest rate on deposits to maintain a given volume of deposits. Simply put, depositors expect lower interest rates on deposits from a capital-rich bank.

The demand for loans is also affected by a bank's capital position relative to its competitors. A bank with a higher capital base faces more pressure from shareholders to earn a higher return. Thus, ceteris paribus, a bank that maintains a higher capital base relative to its competitors charges a higher bank lending rate. Thus while more capital (relative to its competitors) puts the bank in a position to offer more loans, the concomitant pressure to charge a higher lending rate than its competitors tends to reduce loan demand.

The bank maximizes profits subject to the capital-asset ratio constraint. A fraction $(\phi)$ of loans is not recoverable.

$$
\operatorname{Max} \pi=\left(r_{L}-\phi\right) L-r_{D} D+\lambda(K-\mu L)
$$

$\pi=$ Profits earned by bank

$\lambda=$ Lagrange multiplier

We next consider two cases. The first case describes the situation where a bank is not constrained by the capital asset ratio as the capital base maintained exceeds the regulatory minimum. This is the unconstrained case where $\lambda=0$. in the alternative scenario the regulatory constraint is binding. In this case $\lambda>0$.

A bank can set either quantities or rates. Given the balance sheet constraint it is convenient to let a bank choose the level of deposits $D$. We begin by eliminating $L, r_{D}$ and $r_{L}$ using (1), (3) and (4). ${ }^{5}$ The profit function can be restated as

$$
\max _{D} \pi=\frac{\left[g_{0}+g_{2}(K-\bar{K})-K-D+g_{1}\left(\bar{r}_{L}-\phi\right)\right](K+D)}{g_{1}}-\frac{\left[D-f_{0}-f_{2}(K-\bar{K})+f_{1} \bar{r}_{D}\right] D}{f_{1}}
$$

$$
\text { Subject to } \quad[K-\mu(K+D)]
$$

The Lagrangean for the optimization problem can be stated as follows:

$$
\mathcal{L}=\frac{\left[g_{0}+g_{2}(K-\bar{K})-K-D+g_{1}\left(\bar{r}_{L}-\phi\right)\right](K+D)}{g_{1}}-\frac{\left[D-f_{0}-f_{2}(K-\bar{K})+f_{1} \bar{r}_{D}\right] D}{f_{1}}+\lambda[K-\mu(K+D)]
$$

\footnotetext{
${ }^{5}$ As stated earlier, $K$ is exogenous and the bank cannot issue additional capital to compensate a loss.
} 
The two first-order conditions are:

$$
\begin{gathered}
\frac{d \mathcal{L}}{d D}=\frac{g_{0}+g_{2}(K-\bar{K})-2(K+D)+g_{1}\left(\bar{r}_{L}-\phi\right)}{g_{1}}-\frac{2 D-f_{0}-f_{2}(K-\bar{K})+f_{1} \bar{r}_{D}}{f_{1}}-\lambda \mu=0 \\
\frac{d \mathcal{L}}{d \lambda}=(1-\mu) K-\mu D=0
\end{gathered}
$$

The optimal $D$ that maximizes a bank's profit depends on whether or not the bank is constrained by the capital asset ratio.

\section{Unconstrained Case}

When the capital requirement is not binding $(\lambda=0)$ the optimal level of deposits can be obtained by solving equation (8) for $D$ :

$$
D=\frac{f_{1}\left[g_{0}-g_{2} \bar{K}+g_{1}\left(\bar{r}_{L}-\bar{r}_{D}\right)-g_{1} \phi\right]+g_{1}\left(f_{0}-f_{2} \bar{K}\right)+\left(f_{1} g_{2}-2 f_{1}+g_{1} f_{2}\right) K}{2\left(f_{1}+g_{1}\right)}
$$

In an unconstrained environment the parameters of the model play an important role in determining the profit-maximizing level of deposits as do the deposit and lending rates charged by a bank's competitors and the respective capital bases.

How does a bank's balance sheet respond to a loss of capital? Here we have in mind a scenario where the bank's capital declines (through a loss of retained earnings, payment of fines, etc.) relative to the average maintained by its competitors.

\section{A. The Original Model $\left(g_{2}=f_{2}=0\right)$}

Taking the derivative of equation (10) with respect to a bank's exogenous capital base yields:

$$
\frac{d D}{d K}=\frac{-f_{1}}{\left(f_{1}+g_{1}\right)}<0 \text { but }>-1
$$

In the original model by Peek and Rosengren a bank will unambiguously increase its deposits in the wake of a loss of capital if loan demand and deposits are independent of a bank's relative capital position. Seeking more deposits to partially offset the loss of capital is the optimal response given that a bank is not 'bound' by the regulatory capital requirement.

On the asset side of the balance sheet a bank's loan portfolio shrinks. This result follows directly from the balance sheet constraint:

$$
L=D+K
$$

Hence

$$
\frac{d L}{d K}=\frac{g_{1}}{\left(f_{1}+g_{1}\right)}>0 \text { but }<1
$$

A bank's loan portfolio does not fully absorb the loss of capital. It does not shrink on a one-forone basis with the capital base because a bank increases deposits.

B. The Amended Model: $g_{2}>0, f_{2}>0$

Taking the derivative of equation (10) with respect to $K$ yields:

$$
\frac{d D}{d K}=\frac{f_{1}\left(g_{2}-2\right)+g_{1} f_{2}}{2\left(f_{1}+g_{1}\right)}
$$


The sign of this derivative is now indeterminate. Whether the numerator of the expression is positive, negative, or zero depends on the relative size of the key parameters of the model. It is immediately obvious that the sensitivity of loan demand to the relative capital buffer $\left(g_{2}\right)$ and the sensitivity of deposits to the relative capital buffer $\left(f_{2}\right)$ play an instrumental part in determining a bank's reaction to the loss of capital.

If the sensitivity of loans $\left(g_{2}\right)$ to relative capital is sufficiently large so that the coefficient is greater than or equal to 2 , a bank experiencing a capital loss unambiguously reduces deposits. ${ }^{6}$ A large $g_{2}$ means that the demand for a bank's loans declines rapidly when its capital decreases. Now a bank does not really need to collect deposits to make up the lost capital in order to avoid forgoing profitable lending opportunities. If $g_{2}$ is very small, a bank does not lose many profitable lending opportunities even if its capital decreases. In this case, a bank may choose to fund these loans by increasing deposits although it now holds less capital. But even if $g_{2}$ is very small, a bank may still choose to shrink deposits when its capital is declining. This happens if the sensitivity of deposits to relative capital $\left(f_{2}\right)$ is very large. If the demand for deposits decreases very fast in a response to a loss of capital a profit-maximizing bank does not recover deposits even if it increases interest paid on deposits. The optimal response is to shrink deposits.

The response of a bank's loan portfolio to a loss of capital is obtained by taking the derivative of the balance sheet constraint with respect to $K$ and making use of a bank's deposit response to a decrease in its capital.

$$
\frac{d L}{d K}=\frac{f_{1} g_{2}+2 g_{1}+g_{1} f_{2}}{2\left(f_{1}+g_{1}\right)}>0
$$

A bank's optimal response is undoubtedly to shrink its loan portfolio. The size of the loan reduction is, however, less clear. Earlier we pointed out that if $g_{2}$ is greater than or equal to 2 the bank shrinks its deposits. Suppose we retain this assumption and set $g_{2}$ equal to 2 . The response of bank loans to a loss of capital is now given by:

$$
\frac{d L}{d K}=\frac{2\left(f_{1}+g_{1}\right)+g_{1} f_{2}}{2\left(f_{1}+g_{1}\right)}>1
$$

The dollar value of the loan portfolio shrinks by more than the loss of capital. The reason is simple: if the demand for loans falls severely, then there is no need for a bank to seek more deposits to insulate the supply of loans. A bank shrinks its loans because profitable loan opportunities have evaporated.

If $g_{2}$ is small, a bank's loan portfolio could shrink by less than the dollar value of the loss of capital. In this case loan demand does not respond sensitively to the loss of bank capital and profitable loans do not disappear as fast. But yet again, it may be still optimal for a bank to shrink more than one for one even if $g_{2}$ is small. This happens if $f_{2}$ is very large. Recall that $f_{2}$ is the sensitivity of deposits to its capital relative to its competitors'. A large $f_{2}$ means a bank's deposit demand declines fast as its capital shrinks. The only way to counteract the outflow of deposits is to increase the interest paid on deposits. But this may simply not be economical if $f_{2}$ is sufficiently large. Hence an optimizing bank is better off shrinking its deposits and shedding loans by more than the loss of capital.

\footnotetext{
${ }^{6}$ This is a sufficient but not a necessary condition.
} 


\section{Constrained Case}

If the capital ratio is 'binding' $(\lambda \neq 0)$ then the responses of deposits and loans to a capital shock are determined by equation (9).

$$
\begin{gathered}
\frac{d D}{d K}=\frac{1-\mu}{\mu}>0 \\
\frac{d L}{d K}=\frac{1}{\mu}>1
\end{gathered}
$$

If a bank is 'bound' by the regulatory capital requirement, it will behave in the same way as in the original model. The binding capital ratio prevents a bank from replacing capital using deposits. So a bank has to shrink deposits and forgo a lot of profitable loans. Adjustment of the balance sheet is governed only by the concern to satisfy the constraint. The parameters of the demand equations have no role to play.

\section{THE MODEL WITH RESERVES}

In this section we return to the original model but allow a bank to hold reserves as an asset in addition to bank loans. The central bank operates in the background and determines the policy rate $i$. The central bank remunerates reserves held by a trading bank at the policy rate. The opportunity cost of holding reserves is therefore the difference between the lending rate chosen by a trading bank and the policy rate set by the central bank. Bank reserves held are inversely proportional to the gap between the lending rate and the policy rate, plus a constant:

$$
R=h_{0}-h_{1}\left(r_{L}-i\right) \quad h_{1}>0
$$

$R=$ Reserves and $i=$ exogenous policy rate.

The demand relations for loans and deposits are as in the original model:

$$
\begin{array}{rr}
D=f_{0}+f_{1}\left(r_{D}-\bar{r}_{D}\right) & f_{1}>0 \\
L=g_{0}-g_{1}\left(r_{L}-\overline{r_{L}}\right) & g_{1}>0
\end{array}
$$

Because assets can now be held in the form of reserves the balance sheet constraint changes to

$$
L+R=D+K \text {. }
$$

The Lagrangean for the profit maximization problem can now be set up as follows: ${ }^{7}$

$$
\mathcal{L}=r_{L} L+i R-r_{D} D+\lambda(K-\mu(L+R))
$$

\section{Unconstrained Case $(\lambda=0)$}

In this optimization problem the choice variables are $D$ and $R$. Solve equations (18), (19), and (20) fori, $r_{D}$ and $r_{L}$, respectively, and substitute them into the Lagrangean. To eliminate $L$, solve the balance sheet constraint for $L$ and substitute it into equation (22). This results in:

$$
\mathcal{L}=\left(\frac{\left(-D-K+R+g_{0}\right)}{g_{1}}+\overline{r_{L}}\right)(D+K)+\left(\frac{R-h_{0}}{h_{1}}\right) R-\left(\frac{D-f_{0}}{f_{1}}+\overline{r_{D}}\right) D
$$

${ }^{7}$ As $\phi$ is deemed constant throughout we set it equal to zero to avoid cluttering the analysis. 
The first-order conditions are:

$$
\begin{gathered}
\left(\frac{\left.2(-D-K)+R+g_{0}\right)}{g_{1}}+\overline{r_{L}}\right)-\left(\frac{2 D-f_{0}}{f_{1}}+\overline{r_{D}}\right)=0 \\
\frac{D+K}{g_{1}}+\left(\frac{R-h_{0}}{h_{1}}\right)+\frac{R}{h_{1}}=0
\end{gathered}
$$

Combining the first-order conditions yields a "rule" which describes how reserves and deposits are related to each other:

$$
R=\frac{1}{2}\left(h_{0}-\frac{h_{1}}{g_{1}}(D+K)\right)
$$

Reserves and deposits move in opposite directions. To expand $D, r_{D}$ must rise. This forces up $r_{L}$ which in turn induces the bank to decrease reserves. Substituting equation (26) into equation (24) yields the optimal level of deposits maintained by a bank:

$$
\begin{aligned}
& D=-\frac{1}{\left(a+2 / f_{1}\right)}\left(a K+\bar{r}_{\mathrm{D}}-\bar{r}_{L}-\frac{f_{0}}{f_{1}}-\left(\frac{\frac{h_{0}}{2}+g_{0}}{g_{1}}\right)\right. \\
& a=\frac{2}{g_{1}}+\frac{h_{1}}{2 g_{1}^{2}}
\end{aligned}
$$

The balance sheet of the bank responds to a loss of capital as follows:

$$
\begin{array}{r}
\frac{d D}{d K}=-\frac{f_{1}\left(2+\frac{h_{1}}{2 g_{1}}\right)}{f_{1}\left(2+\frac{h_{1}}{2 g_{1}}\right)+2 g_{1}}=C \quad-1<C<0 \\
\frac{d L}{d K}=\frac{h_{1}+2 g_{1}}{f_{1}\left(2+\frac{h_{1}}{2 g_{1}}\right)+2 g_{1}}>0 \\
\frac{d R}{d K}=-\frac{h_{1}}{f_{1}\left(2+\frac{h_{1}}{2 g_{1}}\right)+2 g_{1}}<0
\end{array}
$$

In the unconstrained case the results for deposits and loans in the original model carry over to the present model, albeit in modified form. The size of $g_{1}$ and $h_{1}$ now figures prominently in the determination of the response of a bank's balance sheet. In the wake of a capital loss, a bank seeks additional deposits but shrinks loans. Reserves increase unambiguously. But the absolute size of the adjustment is generally larger for loans than reserves. In the special case though where $g_{1}$ is very small and $h_{1}$ is very large loans tend to shrink by the amount of the increase in reserves. Total assets remain unchanged. Deposits increase by the size of the capital loss. In the opposite case where $g_{1}$ is very large and $h_{1}$ is very small, loans decrease by the size of the capital loss. Reserves and deposits (and hence total liabilities) remain the same.

\section{Constrained Case $(\lambda>0)$}

In this optimization problem the choice variables are $L, R$, and $\lambda .{ }^{8}$ The Lagrangean reads:

$$
\mathcal{L}=\left(\frac{\left(-L+g_{0}\right)}{g_{1}}+\overline{r_{L}}\right)(L+R)+\left(\frac{R-h_{0}}{h_{1}}\right) R-r_{D}(L+R-K)+\lambda(K-\mu(L+R))
$$

\footnotetext{
8 Doing so allows us to eliminate the Lagrange multiplier easily from the first-order conditions. In the current case, we need not worry about $r_{D}$ as it has no role to play in determining $L$ or $R$. The bank's deposit rate vanishes as the first-order conditions are combined.
} 
When the constraint is binding, the first-order conditions of the optimization problem are as follows:

$$
\begin{array}{r}
\frac{d \mathcal{L}}{d L}=-\frac{(L+R)}{g_{1}}+\left(\frac{g_{0}-L}{g_{1}}+\bar{r}_{L}\right)-r_{D}-\lambda \mu=0 \\
\frac{d \mathcal{L}}{d R}=\left(\frac{g_{0}-L}{g_{1}}+\bar{r}_{L}\right)+\frac{\left(R-h_{0}\right)}{h_{1}}+\frac{R}{h_{1}}-r_{D}-\lambda \mu=0 \\
\frac{d \mathcal{L}}{d \lambda}=K-\mu(L+R)=0
\end{array}
$$

Combining equations (32) and (33) eliminates the Lagrange multiplier and the deposit rate. The resulting equation, which describes the optimal trade-off between loans and reserves, is given by

$$
R=\frac{h_{0}}{2+\frac{h_{1}}{g_{1}}}-\frac{L}{\left(2 \frac{g_{1}}{h_{1}}+1\right)}
$$

Substitution of equation (35) into equation (34) yields a bank's optimal provision of loans:

$$
L=-\frac{h_{0}}{2}+\frac{\left(2 \frac{g_{1}}{h_{1}}+1\right)}{2 \mu \frac{g_{1}}{h_{1}}} K
$$

Differentiating equation (36) with respect to $K$ allows us to determine the reaction of a bank to a loss of capital:

$$
\frac{d L}{d K}=\frac{\left(2 \frac{g_{1}}{h_{1}}+1\right)}{2 \mu \frac{g_{1}}{h_{1}}}=\frac{1}{\mu}\left(1+\frac{1}{2 \frac{g_{1}}{h_{1}}}\right)>\frac{1}{\mu}>1
$$

The dollar value of loans decreases by more than the dollar value of the capital loss. Combining this result with equation (35) gives the response of bank reserves to a loss of capital:

$$
\frac{d R}{d K}=-\frac{1}{2 \mu \frac{g_{1}}{h_{1}}}<0
$$

In response to a loss of capital a bank's optimal response is to increase its reserves. Compared to the original one-asset model where under a binding constraint a bank's reduction in loans in the face of a loss of capital amounts to $\frac{1}{\mu}$, in the two-asset model

o the bank cuts its loan portfolio by a greater margin. The additional cut-back of loans flows directly into reserves.

0 the adjustment in the loan portfolio and reserves depends on the ratio of the sensitivity of $g_{1}$ to $h_{1}$.

○ The greater (smaller) $g_{1}$ relative to $h_{1}$, the closer (the less) the response of loans in the two-asset model matches its response in the original model.

While the respective response of loans and reserves to a loss of capital depends on parameters of the model, the response of total assets to a loss of capital depends only on the capital asset ratio parameter. To see this, add up the two responses. Letting $A$ denote total assets, we obtain:

$$
\frac{d A}{d K}=\frac{d L}{d K}+\frac{d R}{d K}=\frac{1}{\mu} .
$$


Using the balance sheet constraint, we can further establish that

$$
\begin{gathered}
\frac{d A}{d K}=\frac{d D}{d K}+1 \text { Or } \\
\frac{d D}{d K}=\frac{1-\mu}{\mu} .
\end{gathered}
$$

Thus we see that the response of total assets and deposits to a loss of capital in the expanded model is governed only by the capital asset ratio parameter just like in the original model.

\section{CONCLUSION}

This note highlights the role of bank capital in financial intermediation. In a simple model of a banking firm we show that an unconstrained optimizing bank shrinks deposits in response to a loss of capital. For this to happen, a bank's loan demand must be very sensitive to its relative capital position. A profit-maximizing bank may also shrink deposits if the loss of capital leads to an outflow of deposits to such an extent that it is not profitable to recoup them by increasing the deposit rate.

This result has an important implication for tests of capital crunches. Based on their findings, Peek and Rosengren (1995) argue that deposits are a better indicator in capital crunch tests than loans. This is because a decrease in capital always reduces loans no matter whether the capital requirement is 'binding' or not. Deposits decrease only if the capital requirement is 'binding'. According to the adjusted model, however, this claim holds only if the sensitivities of deposits and loans to a bank's relative capital position are very small. Hence, just focusing on deposits may not be sufficient to test the severity of a capital crunch.

With reserves in the model, a bank increases reserves in the face of a capital loss. A bank's loan portfolio shrinks more due to a loss of capital if the constraint is binding in the two-asset model compared to the original one-asset model because a bank increases its reserves at the expense of loans. While the size of the contraction of loans and the expansion of reserves depend on both model parameters $\left(g_{1}, h_{1}\right)$ and the capital asset ratio parameter $(\mu)$, the size of the change in total assets and total liabilities is governed only by the capital asset ratio parameter.

\section{References}

Arnold, B., C. Borio, L. Ellis, and F. Moshirian. (2012). "Systemic Risk, Macro prudential Policy Frameworks, Monitoring Financial Systems and the Evolution of Capital Adequacy. "Journal of Banking and Finance, 36: 31253132.

Berger, A., R. Herring, and G. Szego. (1995). "The Role of Capital in Financial Institutions." Journal of Banking \& Finance 19.3-4: 393-430.

Bhattacharya, S. and A.V. Thakor. (1993). "Contemporary Banking Theory”, Journal of Financial Intermediation 3, 2-50.

Peek, Joe and Eric S. Rosengren. (1995). “The Capital Crunch: Neither a Borrower nor a Lender Be.” Journal of Money, Credit and Banking, August, pp. 625-38. 